\title{
Self-Rated Health in University Students from Rio Branco in the Western Brazilian Amazon
}

\author{
Luciana de Mendonça Freire1, Tatiane Dalamaria1,2, Margarida de Aquino Cunha',2, \\ Orivaldo Florencio de Souza ${ }^{1,2 *}$ \\ ${ }^{1}$ Center for Health Sciences and Sports, Federal University of Acre, Rio Branco, Brazil \\ ${ }^{2}$ Graduate Program in Public Health, Federal University of Acre, Rio Branco, Brazil \\ Email: ${ }^{*}$ orivaldofs.ufac@gmail.com
}

Received 12 July 2014; revised 29 August 2014; accepted 13 September 2014

Copyright (C) 2014 by authors and Scientific Research Publishing Inc.

This work is licensed under the Creative Commons Attribution International License (CC BY).

http://creativecommons.org/licenses/by/4.0/

(c) () Open Access

\section{Abstract}

The objective of this study was to determine the prevalence and associated factors of unsatisfactory self-rated health in university students. A cross-sectional study was conducted in graduate students of a Public University in the city of Rio Branco in the Western Brazilian Amazon. The overall prevalence of unsatisfactory self-rated health was $\mathbf{2 3 . 0 \%}$. After adjusting for gender and age, the factors associated with unsatisfactory self-rated health were as follows: sedentarism during leisure time (prevalence ratio (PR): 2.26 ; 95\% CI: 1.56 - 3.29), consuming meals only in restaurants (PR: 1.48; 95\% CI: 1.14 - 1.94), insomnia (PR: 1.86; 95\% CI: 1.50 - 2.30), headaches (PR: 2.17; 95\% CI: 1.52 - 3.09), and back pain (PR: 2.03 ; 95\% CI: 1.58 - 2.60). Thus, a high prevalence of unsatisfactory self-rated health was identified in this group of university students. The findings suggest immediate implementation of programs to promote healthy behaviors and to prevent headaches, back pain and insomnia.

\section{Keywords}

Self-Rated Health, Epidemiological Factors, Students, Cross-Sectional Studies

\section{Introduction}

Health self-ratings reveal the global health status of an individual as a result of the interactions between biological, social, psychological, behavioral and spiritual domains [1]. Investigations of self-rated health are widely

*Corresponding author.

How to cite this paper: Freire, L.M., Dalamaria, T., Cunha, M.A. and Souza, O.F. (2014) Self-Rated Health in University Students from Rio Branco in the Western Brazilian Amazon. Health, 6, 2245-2249.

http://dx.doi.org/10.4236/health.2014.616260 
used in population-based surveys for their ease of application and high reliability, and these investigations can ascertain the effectiveness of health policies, actions and services for the population [1]. In addition, this approach can predict the occurrence of morbidity and mortality [2].

In Brazil, a number of studies have been conducted to assess self-rated health across many different segments of the population [3] [4]. An important national telephone survey involving 27 major Brazilian cities revealed a greater prevalence of poor self-rated health in women, elderly, those with less schooling, those with a sedentary job and those who reside in the North and Northeastern regions of the country [4]. In a study in the city of Rio Branco, located in Brazil's Northern region, Bezerra et al. [5] found that female gender, older age and low monthly income were associated with unsatisfactory self-rated health. However, no surveys to date have been conducted to determine perceived health among University students residing in the Northern region of Brazil.

Information from self-rated health helps inform the implementation of public policies to promote healthy behavior and to prevent morbidities in University students. Therefore, the objective of this study was to determine the prevalence of unsatisfactory self-rated health and its associated factors in university students in the city of Rio Branco, Brazil.

\section{Methods}

A cross-sectional study was carried out between August and November 2010. The study population consisted of 4500 students enrolled in 34 undergraduate courses at a public University in the city of Rio Branco in northern Brazil, which is more specifically located the Western Brazilian Amazon. Two-stage cluster sampling was used to probabilistically select the students. The primary sampling units were the courses, and the secondary units were the study periods in the courses. Subsequently, all university students were randomly selected in courses and periods and were recruited to take part in the data collection process. To be included in the study, students had to be enrolled in and attending an undergraduate course at the University under study. Details of the sampling plan can be found in Ramalho et al. [6]. This project was analyzed and approved by the Ethics Committee for Human Research at the Federal University of Acre.

A structured questionnaire was used to collect the following information: demographic and socioeconomic characteristics, life habits, self-reported symptoms and self-rated health. Economic class was established as per the criteria of the Brazilian Association of Research Companies (ABEP) [7] into 5 classes, which were A, B, C, $\mathrm{D}$ and $\mathrm{E}$. For the analysis, responses were recategorized into a rich class ( $\mathrm{A}$ and $\mathrm{B}$ ) and a poor class (C, D and E). The occupational status variable was categorized into the following classifications: "Working" (remunerated activities, except for scholarships received for teaching, research, or activities in extension programs undertaken at the University) and "Not working". Students' living arrangements were categorized as living with parents, partner (married or stable union), friends or alone. The students' number of children was categorized as follows: no children, 1 child, and 2 or more children.

Information on the students' weekly frequency and duration per session of physical activities during leisure time were collected. Their intensity of physical activities was determined according to Ainsworth et al. [8]. The physical activity during leisure time variable was categorized according to the criteria described by Haskell et al. [9] into active and sedentary. Students' main venues for meals were categorized into three locales as follows: at home only; at home and in restaurants; and in restaurants only. Self-reported symptoms were identified by posing the following question: "In the last 30 days, have you experienced any of the following symptoms: headache, back pain or insomnia?". The possible answers for perceived symptoms were "present" or "absent".

The dependent variable, self-rated health, was measured by asking the question: "How do you rate your health status?". Responses to the question were categorized into excellent, good, regular and poor, according to the classification system used by the Brazilian Ministry of Health [4] in a national-level survey. Responses were consolidated to give satisfactory (excellent and good) and unsatisfactory (regular and poor) ratings for the analysis.

The collected data were keyed into the EpiData program using double data entry. Subsequently, statistical analyses were performed using the Stata ${ }^{\mathrm{TM}} 12$ software program. The prevalence of unsatisfactory self-rated health by gender and age group was calculated along with the respective 95\% confidence (95\% CI) intervals. Prevalence ratios with respective 95\% CIs for unsatisfactory self-rated health according to the independent variables, with and without adjusting for gender and age group, were calculated using generalized linear models. These models used a binomial distribution with a log relationship and robust standard error. Statistical power 
was calculated a posteriori using the GPower 3.1 software program.

\section{Results}

Among the 874 students recruited, $38.4 \%$ were men, and $61.6 \%$ were women. Of the total sample, $62.6 \%$ were $\leq$ 24 years of age and $37.4 \% \geq 25$ years of age. None of the students were categorized into economic class E. The overall prevalence of unsatisfactory self-rated health was $23.2 \%$ for this group of university students. Stratified by age group, the greatest prevalence was in women compared with men (Table 1).

The variables for physical activity during leisure time, venue for meals, body mass index and perceived headache, back pain and insomnia were associated with unsatisfactory self-rated health (Table 2). When examining the life habits, sedentarism was associated with a 2.36-fold greater prevalence of unsatisfactory self-rated health. Consuming "meals in restaurants only" had a prevalence ratio that was 1.39 times higher than consuming "meals at home only”. Students who reported headaches and back pain had a prevalence ratio of unsatisfactory self-rated health that was double the PR of students not reporting these symptoms. Students reporting insomnia had a 1.88 times greater likelihood of unsatisfactory self-rated health compared with students without this symptom. The a posteriori analysis of statistical power at the $80 \%$ level revealed that a prevalence ratio $\geq 1.20$ was statistically significant $(\mathrm{p}=0.05)$.

\section{Discussion}

The prevalence of unsatisfactory self-rated health was $23.2 \%$ among this group of university students. This high prevalence was similar to that found in a population-based survey conducted in the city of Rio Branco that involved undergraduate and graduate students [5]. The main factors associated with unsatisfactory self-assessment were female gender, poor economic class, sedentary classification, consuming meals in restaurants only, and reporting symptoms of headache, back pain and insomnia.

A higher prevalence of unsatisfactory self-rated health was found among female students. Similar results were observed in other studies of self-rated health [10] [11]. In Brazil, a survey carried out by the National Household Survey (2008) revealed that women used healthcare services more often than men [3]. This finding may be explained by the fact that women are more sensitive to physiological changes due to morbidities [12] [13]. In addition, constant self-care of their bodies for beauty and health may lead to these greater sensitivities in health selfratings.

After adjusting for gender and age group in the present study, economic class and living arrangement were found to have no effect on perceived health of the university students, which is in contrast to previous Brazilian studies [3] [5] [14]. Similarly, the double daily burden of studying at university and working or caring for children was not found to be associated with unsatisfactory self-rated health.

The association observed here between sedentarism during leisure time and unsatisfactory self-rated health corroborates the findings of national and international studies [15] [16]. This association is consistent with the benefits of physical activity for health and well-being. However, given the possibility of reverse causality, this association should be analyzed with caution. Hence, it is not possible to affirm whether students were sedentary because they have unsatisfactory perceived health statuses or conversely, they have adopted sedentary behaviors because of poor perceived health.

Unsatisfactory self-rated health had a statistically significant association with only consuming meals in restaurants. Similarly, Silva [17] found that inadequate meals were associated with unsatisfactory self-rated health in university students living in the Northeastern region of Brazil. This association may be due to the long periods spent studying or, in some cases, to double shifts of daily activity (university and working). For reasons of

Table 1. Prevalence of unsatisfactory self-rated health by age and gender in university students.

\begin{tabular}{cccc}
\hline & Both genders & \multicolumn{2}{c}{ Gender } \\
\cline { 3 - 4 } & $\%(95 \% \mathrm{CI})$ & $\%(95 \% \mathrm{CI})$ & $\%(95 \% \mathrm{CI})$ \\
\cline { 3 - 4 }$\leq 24$ years & $24.1(20.4 ; 27.8)$ & $20.5(14.6 ; 26.3)$ & $26.1(21.4 ; 30.8)$ \\
$\geq 25$ years & $21.7(17.1 ; 26.3)$ & $16.1(9.7 ; 22.5)$ & $25.8(19.4 ; 32.2)$ \\
All & $23.2(20.4 ; 26.0)$ & $19.3(15.1 ; 23.5)$ & $25.6(21.9 ; 29.3)$ \\
\hline
\end{tabular}


Table 2. Association of unsatisfactory self-rated health according to socioeconomic characteristics, life habits and selfreported symptoms in university students.

\begin{tabular}{|c|c|c|c|c|c|c|c|}
\hline Categories & $\mathrm{n}$ & $\%$ & Crude PR & (95\% CI) & Adjusted PR* & $(95 \% \mathrm{CI})$ & $\mathrm{p}$ \\
\hline \multicolumn{8}{|l|}{ Economic class } \\
\hline Rich class & 392 & 20.1 & 1 & & & & \\
\hline Poor class & 475 & 26.1 & 1.29 & $(1.00 ; 1.67)$ & & & \\
\hline \multicolumn{8}{|l|}{ Occupational status } \\
\hline Not working & 547 & 24.8 & 1 & & & & \\
\hline Working & 324 & 20.6 & 0.83 & $(0.63 ; 1.09)$ & & & \\
\hline \multicolumn{8}{|l|}{ Living arrangement } \\
\hline Parents & 450 & 22.4 & 1 & & & & \\
\hline Partner & 223 & 22.8 & 1.01 & $(0.68 ; 1.50)$ & & & \\
\hline Friends & 136 & 25.0 & 1.11 & $(0.70 ; 1.76)$ & & & \\
\hline Alone & 60 & 28.3 & 1.26 & $(0.78 ; 2.02)$ & & & \\
\hline \multicolumn{8}{|l|}{ Number of children } \\
\hline No children & 623 & 22.1 & 1 & & & & \\
\hline 1 child & 137 & 25.5 & 1.15 & $(0.82 ; 1.61)$ & & & \\
\hline 2 or more children & 107 & 26.1 & 1.18 & $(0.76 ; 1.83)$ & & & \\
\hline \multicolumn{8}{|l|}{ Physical activity during leisure time } \\
\hline Active & 361 & 11.8 & 1 & & 1 & & \\
\hline Sedentary & 511 & 27.9 & 2.36 & $(1.68 ; 3.30)$ & 2.26 & $(1.56 ; 3.29)$ & 0.000 \\
\hline \multicolumn{8}{|l|}{ Venue for meals } \\
\hline At home only & 304 & 21.0 & 1 & & 1 & & \\
\hline At home and in restaurants & 438 & 23.1 & 1.10 & $(0.82 ; 1.48)$ & 1.15 & $(0.85 ; 1.56)$ & 0.338 \\
\hline In restaurants only & 119 & 29.4 & 1.39 & $(1.04 ; 1.87)$ & 1.48 & $(1.14 ; 1.94)$ & 0.003 \\
\hline \multicolumn{8}{|l|}{ Headache } \\
\hline Absent & 274 & 12.7 & 1 & & 1 & & \\
\hline Present & 600 & 28.0 & 2.19 & $(1.59 ; 3.01)$ & 2.17 & $(1.52 ; 3.09)$ & 0.000 \\
\hline \multicolumn{8}{|l|}{ Back pain } \\
\hline Absent & 380 & 14.7 & 1 & & 1 & & \\
\hline Present & 494 & 29.9 & 2.06 & $(1.63 ; 2.62)$ & 2.03 & $(1.58 ; 2.60)$ & 0.000 \\
\hline \multicolumn{8}{|l|}{ Insomnia } \\
\hline Absent & 636 & 18.7 & 1 & & 1 & & \\
\hline Present & 238 & 35.2 & 1.88 & $(1.54 ; 2.30)$ & 1.86 & $(1.50 ; 2.30)$ & 0.000 \\
\hline
\end{tabular}

convenience, these factors may lead students to only consuming meals in restaurants

The association identified between unsatisfactory self-rated health and perceived symptoms in the present study corroborate both national and international findings [1] [14] [18]. Dowd [1] and Franks et al. [18] observed that unsatisfactory self-rated health was strongly associated with morbidity and mortality in groups with higher levels of schooling. Thus, university students reporting unsatisfactory self-rated health are more susceptible to the occurrence of morbidities.

\section{Conclusion}

Finally, a high prevalence of unsatisfactory self-rated health was detected in this group of university students. The findings suggest immediate implementation of programs to promote healthy behaviors and to prevent insomnia, headaches and back pain.

\section{References}

[1] Picard, M., Juster, R. and Sabiston, C. (2013) Is the Whole Greater than the Sum of the Parts? Self-Rated Health and 
Transdisciplinarity. Health, 5, 24-30. http://dx.doi.org/10.4236/health.2013.512A004

[2] Dowd, J.B. and Zajacova, A. (2007) Does the Predictive Power of Self-Rated Health for Subsequent Mortality Risk Vary by Socioeconomic Status in the US? International Journal of Epidemiology, 36, 1214-1221. http://dx.doi.org/10.1093/ije/dym214

[3] Dachs. J., Norberto, W. and Santos, A.P.R. (2006) Health Self-Rating in Brazil: Analysis of Data of the PNAD/2003. Ciência e Saúde Coletiva, 11, 887-894. http://dx.doi.org/10.1590/S1413-81232006000400012

[4] Brazilian Ministry of Health (2011) Vigitel Brazil 2010: Protective and Risk Factors for Chronic Diseases by Telephone Survey. Brazilian Ministry of Health, Brasília, 110.

[5] Bezerra, P.C.L., Optiz, S.P., Koifman, R.J. and Muniz, P.T. (2011) Self-Rated Health and Associated Factors in Adults: A Population Survey in Rio Branco, Acre State, Brazil, 2007-2008. Cadernos de Saúde Pública, 27, 2441-2451. http://dx.doi.org/10.1590/S0102-311X2011001200015

[6] Ramalho, A.A., Dalamaria, T. and Souza, O.F. (2012) Regular Consumption of Fruits and Vegetables by University Students in Rio Branco, Acre State, Brazil: Prevalence and Associated Factors. Cadernos de Saúde Pública, 28, 14051413. http://dx.doi.org/10.1590/S0102-311X2012000700018

[7] Associação Brasileira de Empresas de Pesquisa (2011) Critério de classificação econômica Brasil. http://www.abep.org/new/criterioBrasil.aspx

[8] Ainsworth, B.E., Haskell, W.L., Whitt, M.C. and Irwin, M.L. (2000) Compendium of Physical Activities: An Update of Activity Codes and MET Intensities. Medicine and Science in Sports and Exercise, 32, S498-S504. http://dx.doi.org/10.1097/00005768-200009001-00009

[9] Haskell, W.L., Lee, I.M., Pate, R.R., Powell, K.E., Blair, S.N., Franklin, B.A., Macera, C.A., Health, G.W., Thompson, P.D. and Balman, A. (2007) Physical Activity and Public Health: Updated Recommendation for Adults from the American College of Sports Medicine and the American Heart Association. Circulation, 116, 1081-1093. http://dx.doi.org/10.1161/CIRCULATIONAHA.107.185649

[10] Boune, P.A. (2009) Social Determinants of Health in Jamaica: Are There Differences between the Sexes, and Area of Residences? HealthMED, 3, 359-373.

[11] Shimidt, M. (2012) Predictors of Self-Rated Health and Lifestyle Behaviours in Swedish University Students. Global Journal of Health Science, 4, 1-14.

[12] Meurer, L.N., Layde, P.M. and Guse, C.E. (2001) Self-Rated Health Status: A New Vital Sign for Primary Care? World Medical Journal, 100, 35-39.

[13] Shadbolt, B. (1997) Some Correlates of Self-Rated Health for Australian Women. American Journal of Public Health, 87, 951-956. http://dx.doi.org/10.2105/AJPH.87.6.951

[14] Peres, M.A., Maciero, A.V., Longo, G.Z., Rocha, G.C., Matos, I.B., Najnie, K., et al. (2010) Self-Rated Health among Adults in Southern Brazil. Revista de Saúde Pública, 44, 901-911. http://dx.doi.org/10.1590/S0034-89102010000500016

[15] Molarius, A., Berglund, K., Eriksson, C., Lamb, E.M., Nordstro, E., Eriksso, H.G., et al. (2007) Socioeconomic Conditions, Lifestyle Factors, and Self-Rated Health among Men and Women in Sweden. European Journal of Public Health, 17, 125-133. http://dx.doi.org/10.1093/eurpub/ckl070

[16] Pagotto, V., Nakatani, A.Y.K. and Silveira, E.A. (2011) Factors Associated with Poor Self-Rated Health in Elderly Users of the Brazilian Unified National Health System. Cadernos de Saúde Pública, 27, 1593-1602. http://dx.doi.org/10.1590/S0102-311X2011000800014

[17] Silva, D.A.S. (2012) Lifestyle Indicators and Negative Health Self-Assessment among Students of a Public University in Northeastern Brazil. Revista Brasileira de Atividade Física e Saúde, 17, 263-269.

[18] Franks, P., Gold, M.R. and Fiscella, K. (2003) Sociodemographics, Self-Rated Health and Mortality in US. Social Science and Medicine, 56, 2505-2514. http://dx.doi.org/10.1016/S0277-9536(02)00281-2 
Scientific Research Publishing (SCIRP) is one of the largest Open Access journal publishers. It is currently publishing more than 200 open access, online, peer-reviewed journals covering a wide range of academic disciplines. SCIRP serves the worldwide academic communities and contributes to the progress and application of science with its publication.

Other selected journals from SCIRP are listed as below. Submit your manuscript to us via either submit@scirp.org or Online Submission Portal.
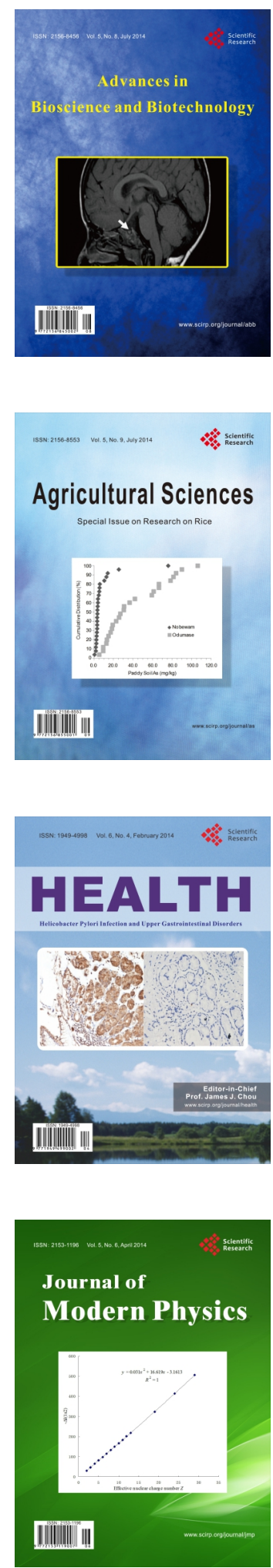
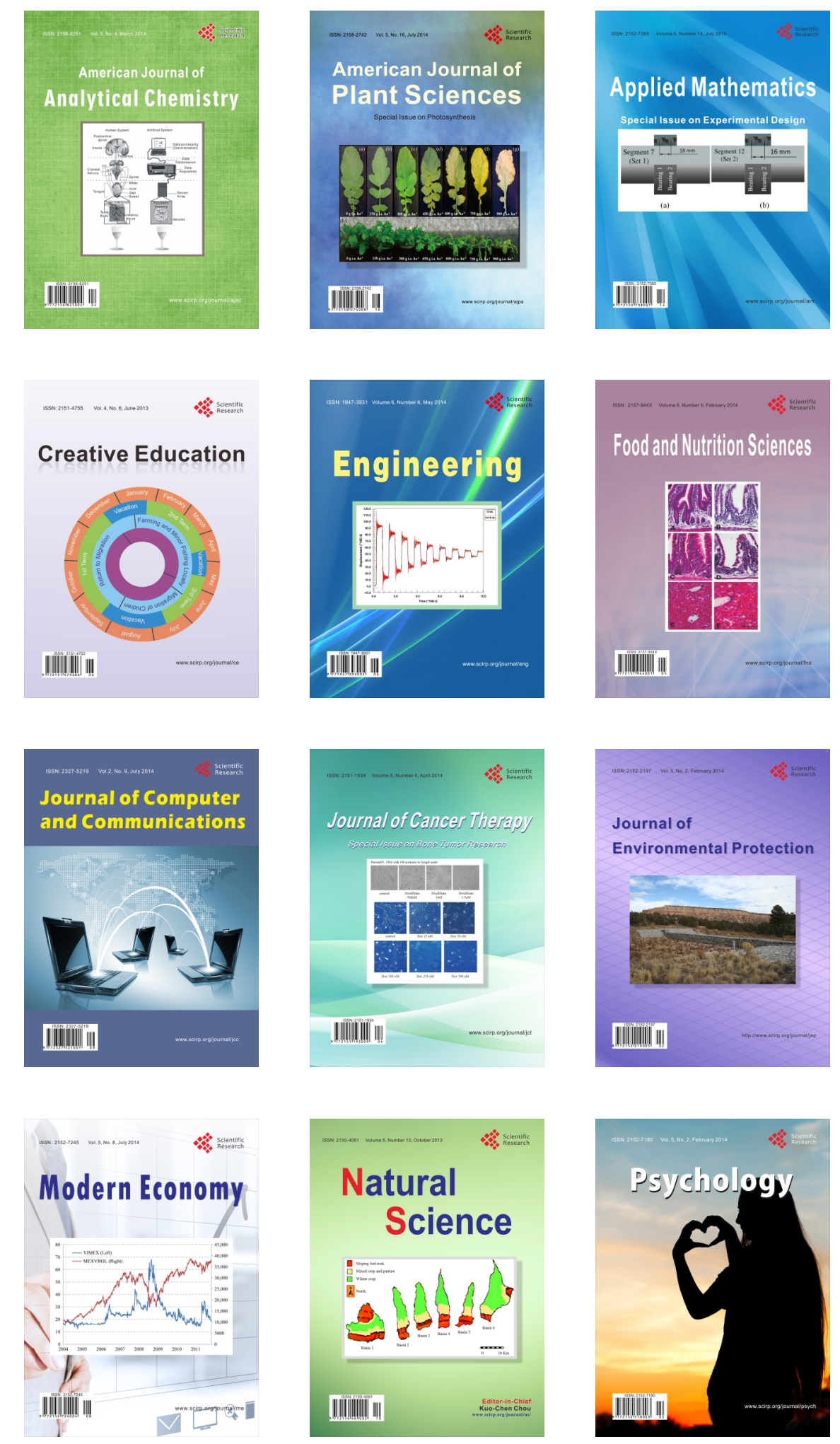